\title{
The relationship between surgical site drains and reoperation for wound-related complications following posterior cervical spine surgery: a multicenter retrospective study
}

Presented at the 2018 AANS/CNS Joint Section on Disorders of the Spine and Peripheral Nerves

\author{
Daniel B. Herrick, BA, ${ }^{1,2}$ Joseph E. Tanenbaum, BA, ${ }^{3-5}$ Marc Mankarious, BA, ${ }^{1,2}$ \\ Sagar Vallabh, MS, ${ }^{3,4}$ Eitan Fleischman, BA, ${ }^{4,6}$ Swamy Kurra, MD, ${ }^{7}$ Shane M. Burke, MD, MBA, ${ }^{1,2}$ \\ Marie Roguski, MD, MPH, ${ }^{1,2}$ Thomas E. Mroz, MD, ${ }^{4,8,9}$ William F. Lavelle, MD, ${ }^{7}$ \\ Jeffrey E. Florman, MD, ${ }^{10}$ and Ron I. Riesenburger, MD ${ }^{1,2}$
}

\begin{abstract}
${ }^{1}$ Department of Neurosurgery, Tufts Medical Center; ${ }^{2}$ Department of Neurosurgery, Tufts University School of Medicine, Boston, Massachusetts; ${ }^{3}$ Case Western Reserve University School of Medicine, Cleveland; ${ }^{4}$ Center for Spine Health, Cleveland Clinic, Cleveland; ${ }^{5}$ Department of Epidemiology and Biostatistics, Case Western Reserve University, Cleveland, Ohio; ${ }^{6}$ Sackler School of Medicine, Tel Aviv University, Tel Aviv, Israel; ${ }^{7}$ Department of Orthopedic Surgery, SUNY Upstate Medical University, Syracuse, New York; ${ }^{8}$ Department of Neurosurgery, Cleveland Clinic, Cleveland; ${ }^{9}$ Cleveland Clinic Lerner College of Medicine, Cleveland Clinic, Cleveland, Ohio; and ${ }^{10}$ Neuroscience Institute, Maine Medical Center, Portland, Maine
\end{abstract}

OBJECTIVE Use of surgical site drains following posterior cervical spine surgery is variable, and its impact on outcomes remains controversial. Studies of drain use in the lumbar spine have suggested that drains are not associated with reduction of reoperations for wound infection or hematoma. There is a paucity of studies examining this relationship in the cervical spine, where hematomas and infections can have severe consequences. This study aims to examine the relationship between surgical site drains and reoperation for wound-related complications following posterior cervical spine surgery.

METHODS This study is a multicenter retrospective review of 1799 consecutive patients who underwent posterior cervical decompression with instrumentation at 4 tertiary care centers between 2004 and 2016. Demographic and perioperative data were analyzed for associations with drain placement and return to the operating room.

RESULTS Of 1799 patients, 1180 (65.6\%) had a drain placed. Multivariate logistic regression analysis identified history of diabetes (OR 1.37, $p=0.03$ ) and total number of levels operated (OR 1.32, $p<0.001)$ as independent predictors of drain placement. Rates of reoperation for any surgical site complication were not different between the drain and nodrain groups $(4.07 \%$ vs $3.88 \%, p=0.85)$. Similarly, rates of reoperation for surgical site infection $(1.61 \%$ vs $2.58 \%, p=$ $0.16)$ and hematoma $(0.68 \%$ vs $0.48 \%, p=0.62)$ were not different between the drain and no-drain groups. However, after adjusting for history of diabetes and the number of operative levels, patients with drains had significantly lower odds of returning to the operating room for surgical site infection (OR 0.48, $p=0.04$ ) but not for hematoma (OR 1.22, $p=0.77$ ). CONCLUSIONS This large study characterizes current practice patterns in the utilization of surgical site drains during posterior cervical decompression and instrumentation. Patients with drains placed did not have lower odds of returning to the operating room for postoperative hematoma. However, the authors' data suggest that patients with drains may be less likely to return to the operating room for surgical site infection, although the absolute number of infections in the entire population was small, limiting the analysis.

https://thejns.org/doi/abs/10.3171/2018.5.SPINE171313

KEYWORDS cervical spine; surgical site drain; surgical site infection; seroma; epidural hematoma

ABBREVIATIONS EBL = estimated blood loss; SCIP = Surgical Care Improvement Project; SSI = surgical site infection.

SUBMITTED November 30, 2017. ACCEPTED May 11, 2018.

INCLUDE WHEN CITING Published online September 14, 2018; DOI: 10.3171/2018.5.SPINE171313. 
$\mathrm{P}$ OSTOPERATIVE spinal epidural hematoma and surgical site infection (SSI) are devastating complications following posterior cervical spine surgery, with reported incidences of $1.5 \%$ and $1 \%-6 \%, 18,19,24,27$ respectively. Closed suction surgical site drains are commonly used after posterior cervical spine surgery, as they are thought to prevent hematomas, seromas, and SSIs. Drains can assist in removal of blood products and other fluid from the surgical site, and thus it is thought that the drain can serve as a means of decompression of closed spaces after surgery. Conversely, the drain can serve as a conduit for organisms to infect an otherwise clean surgical site. While the theoretical risks and benefits of postoperative drain use have been established, the use of surgical site drains remains variable, and the clinical benefits are controversial.

There are only a small number of studies examining the role of postoperative surgical site drains in the posterior cervical spine. One study examined the role of surgical site drains with and without alcohol foam or vancomycin powder following posterior cervical spine surgery and concluded that the drain with or without alcohol foam or vancomycin was associated with reduced odds of postoperative infections compared to the control group..$^{20}$ However, this group studied consecutive cases of only one surgeon and did not test whether there was an association between drain use and poor wound-related postoperative outcomes such as hematoma and wound dehiscence. In light of the paucity of studies regarding the use of surgical site drains in posterior cervical spine surgery, we sought to better understand the association between surgical site drains and reoperation after posterior cervical spine surgery in a large cohort from multiple centers.

\section{Methods}

\section{Patient Population}

Records of consecutive adult patients undergoing posterior cervical decompression and instrumentation at 4 tertiary care centers between 2004 and 2016 were reviewed. Patients who underwent cervical and lumbar operations with 2 separate incisions were excluded. However, patients undergoing anterior cervical spine surgery in the same operation were not excluded, as we considered this one disease process. Patients with malignant disease of the spine were excluded. Per the Surgical Care Improvement Project (SCIP) measures, all patients were administered prophylactic antibiotics within 1 hour prior to surgical incision. Antisepsis preparation was performed for all patients according to the current Centers for Disease Control and Prevention guideline at the time of operation. The Cleveland Clinic Foundation, Maine Medical Center, SUNY Upstate Medical University, and Tufts University institutional review boards approved the study.

\section{Clinical Data Collection}

Demographic and clinical variables were collected retrospectively through review of electronic medical records and paper charts. Operative notes were reviewed to determine whether a surgical site drain was placed. Patients were stratified into 2 groups: drain and no drain. Surgery was considered elective if the patient was scheduled for surgery after an outpatient visit. Nonelective surgeries included those in patients who were transferred from an outside hospital, presented to the emergency department, or had changes in neurological function requiring decompressive surgery during a hospital stay. Patients were considered to have a history of cervical spine surgery if any cervical vertebrae had been operated on previously. Superficial neck operations did not qualify. Operative levels included all levels involved in either decompression or instrumentation. Postoperative length of stay is defined as the length of time in days between the operation and hospital discharge. Total length of stay is defined as the total number of hospital days between hospital admission and discharge.

\section{Outcomes}

All operations occurring after the initial operation on the posterior cervical spine were reviewed. We determined a second operation to be potentially related to the drain status if the second operation occurred within 90 days of the first operation. Hematoma was defined as an epidural hematoma with acute neurological deterioration with visualization of the hematoma by the surgeon on reoperation. Infections were identified by clinical signs and verified by positive culture of the wound if possible. A principal investigator was blinded to drain placement and reviewed all reoperations to determine whether they were potentially related to drain status. The principal investigator reviewed the preoperative and postoperative diagnoses listed on the operative note and thoroughly reviewed the subsequent written details of the operation. Any diagnosis or written text indicative of a hematoma, bleeding, seroma, infection, dehiscence, purulent fluid, or phlegmon was potentially included as related to drain status. Patients who underwent reoperation within 90 days for inadequate decompression, adjacent-segment disease, or acute hardware failure were not included in the reoperation group. Any mention alluding to drain placement was removed from the operative notes prior to review by the principal investigator. The second operation was a clinical endpoint. Further operations were not considered.

\section{Statistical Analysis}

Patients who had a surgical site drain placed were compared with those who did not have a surgical site drain placed for demographic, clinical, and perioperative characteristics. The 2 populations (drain vs no drain) were compared using chi-square analysis, Fisher's exact test, the Student t-test, and the Kruskal-Wallis 1-way ANOVA as appropriate. Backward step-wise multivariate logistic regression models were used to identify independent predictors of surgical site drain placement. Variables with $\mathrm{p} \leq$ 0.1 on univariate logistic regression analyses were included in the backward step-wise multivariate models. Variables with $\mathrm{p}<0.2$ were retained in the backward step-wise models. Results are presented as median (IQR) or mean \pm standard deviation, unless otherwise specified; $\mathrm{p} \leq 0.05$ was considered statistically significant. Statistical analyses were performed using Stata/SE version 11.2 (StataCorp). 
TABLE 1. Patient demographics and clinical characteristics

\begin{tabular}{lccc}
\hline & $\begin{array}{c}\text { Drain } \\
(\mathrm{n}=1180)\end{array}$ & $\begin{array}{c}\text { No Drain } \\
(\mathrm{n}=619)\end{array}$ & $\begin{array}{c}\mathrm{p} \\
\text { Value }\end{array}$ \\
\hline Mean age $\pm \mathrm{SEM}, \mathrm{yrs}$ & $63.6 \pm 0.4$ & $62.3 \pm 0.6$ & 0.06 \\
\hline Female sex, $\mathrm{n}(\%)$ & $465(39.4)$ & $257(41.5)$ & 0.39 \\
\hline Mean BMI $\pm \mathrm{SEM}, \mathrm{kg} / \mathrm{m}^{2}$ & $28.8 \pm 0.3$ & $28.3 \pm 0.3$ & 0.20 \\
\hline Current smoker, $\mathrm{n}(\%)$ & $240(20.8)$ & $146(23.8)$ & 0.15 \\
\hline Hx rheumatoid arthritis, $\mathrm{n}(\%)$ & $94(8.0)$ & $39(6.3)$ & 0.19 \\
\hline Hx type 2 diabetes, $\mathrm{n}(\%)$ & $281(24.1)$ & $115(18.6)$ & 0.008 \\
\hline Hx cervical spine surgery, $\mathrm{n}(\%)$ & $250(21.5)$ & $171(27.8)$ & 0.003 \\
\hline Median no. (IQR) of op levels & $4(4-6)$ & $4(2-5)$ & $<0.001$ \\
\hline Mean EBL \pm SEM, $\mathrm{ml}$ & $255.2 \pm 12.1$ & $199.8 \pm 12.0$ & 0.003 \\
\hline
\end{tabular}

$\mathrm{Hx}=$ history of.

\section{Results}

A total of 1851 patients were identified who underwent posterior cervical decompression and instrumentation from 2004 to 2016. Of these patients, 2 patients were excluded for having both lumbar and cervical surgery in the same operation, and 50 patients were excluded for having incomplete medical record information. Thus, 1799 patients were included in the analysis. Fifty surgeons operated on study patients among the 4 hospitals contributing to the study.

\section{Determinants of Drain Placement}

Of the 1799 patients included in the study, $1180(65.6 \%)$ had a surgical site drain placed. Age, sex, BMI, smoking status, and history of rheumatoid arthritis were not statistically different between the drain and no-drain groups (Table 1). However, between the drain and no-drain groups, history of type 2 diabetes $(24.1 \%$ vs $18.6 \%$, respectively; $\mathrm{p}=0.008)$, history of cervical spine surgery $(21.5 \%$ vs $27.8 \%$, respectively; $\mathrm{p}=0.003$ ), median number of operative levels (4 [IQR 4-6] vs 4 [IQR 2-5], respectively; $\mathrm{p}<$ 0.001 ), and estimated blood loss (EBL; $255.2 \pm 12.1 \mathrm{ml}$ vs $199.8 \pm 12.0 \mathrm{ml}$ [SEM], respectively; $\mathrm{p}=0.003$ ) were statistically significantly different (Table 1).

Drain placement was variable between hospitals (Fig. 1A). Drain placement ranged between $24.3 \%$ and $80.0 \%$ at the 4 hospitals $(\mathrm{p}<0.001)$. Furthermore, drain placement was variable between surgeons in each hospital practice (Fig. 1B), with the following drain placement rates at each hospital: $2.0 \%-41.7 \%, 33.3 \%-95.1 \%, 26.5 \%-99.0 \%$, and $67.5 \%-93.1 \%$ among surgeons who operated on at least 20 patients in the study. The overall rate of drain placement for each surgeon in the study contributing at least 20 patients ranged from $2.0 \%$ to $99.0 \%$ (Fig. 1C).

On univariate analysis, surgical site drain placement was associated with the following demographic and clinical characteristics: history of cervical spine surgery (OR $0.71, \mathrm{p}=0.003)$, history of type 2 diabetes $(\mathrm{OR} 1.39, \mathrm{p}=$ $0.008)$, total number of levels operated (OR 1.37, p <0.001), and EBL (OR 1.01 per $10 \mathrm{ml}, \mathrm{p}=0.01$ ) (Table 2). Independent predictors of surgical site drain placement (Table 2) were history of type 2 diabetes (OR $1.37, \mathrm{p}=0.02$ ), history of cervical spine surgery (OR $0.66, \mathrm{p}<0.001)$, and
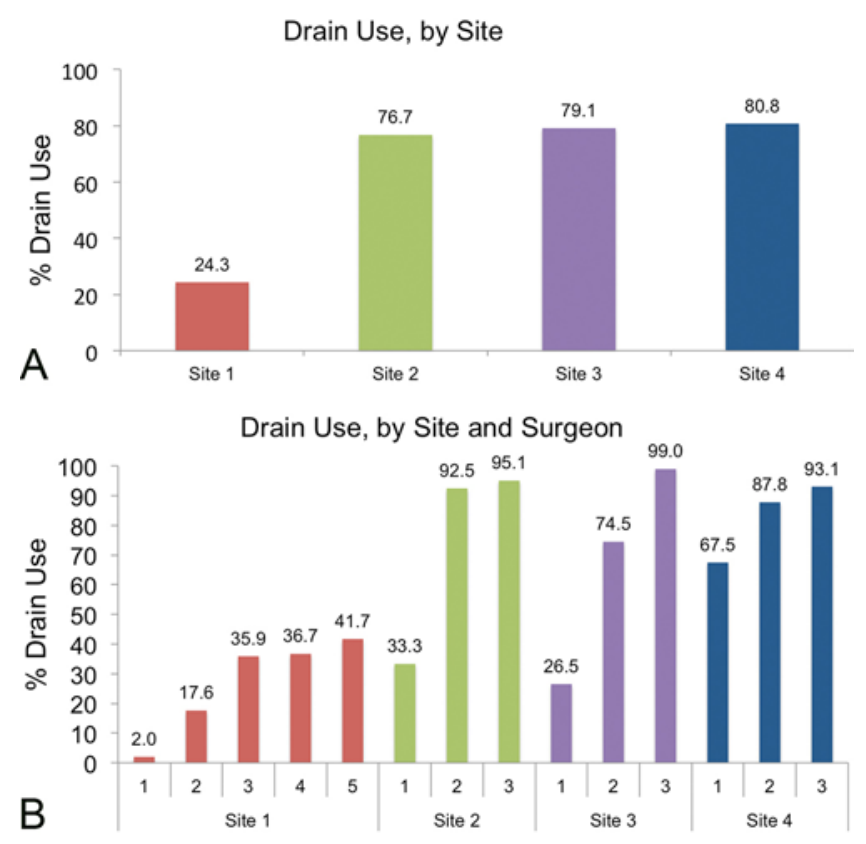

Drain Use, by Site and Surgeon

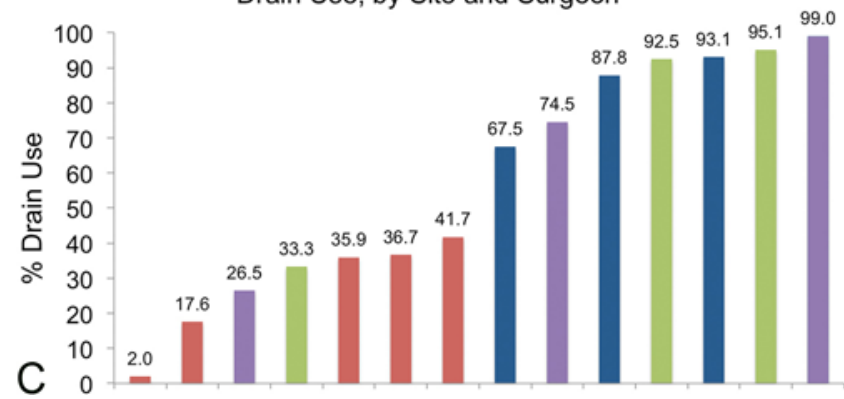

FIG. 1. Bar graphs demonstrating the rate of drain use at each institution $(A)$, by surgeon grouped by institution $(B)$, and by surgeon without grouping by institution (C). Numbers immediately below the $x$-axis represent individual surgeons. Bar colors indicate the sites contributing patients to the study: red (site 1), green (site 2), purple (site 3), and blue (site 4). Figure is available in color online only.

total number of levels operated (OR 1.38, $\mathrm{p}<0.001)$. After adjusting for hospital where the surgery was performed, history of type 2 diabetes (OR 1.37, $\mathrm{p}=0.03$ ) and total number of levels operated (OR 1.32, p < 0.001) were both associated with drain placement. The area under the curve from this analysis was 0.77 compared with 0.65 when the model was not adjusted for the hospital where surgery took place.

\section{Outcomes Associated With Drain Placement}

Reoperation unrelated to hardware or adjacent-segment disease occurred in 72 of 1799 (4.00\%) patients within 90 days of the initial operation. On univariate analysis, reoperation rates were similar between the drain and no-drain groups (4.07\% vs 3.88\%, respectively; $\mathrm{p}=0.85$ ) (Table 3 ). The overall rates of reoperation were as follows for the various subgroups: hematoma, $0.61 \%$; seroma, $0.39 \%$; SSI, $1.95 \%$; wound dehiscence, $1.00 \%$; and other, $0.22 \%$. Rates of reoperation between the drain and no-drain groups for hematoma $(0.68 \%$ vs $0.48 \%, \mathrm{p}=0.62)$, seroma $(0.51 \%$ vs 
TABLE 2. Demographic and clinical predictors of drain placement

\begin{tabular}{|c|c|c|c|c|c|c|c|c|c|}
\hline & \multicolumn{3}{|c|}{ Univariate Analysis } & \multicolumn{3}{|c|}{ Multivariate Analysis } & \multicolumn{3}{|c|}{ Multivariate Analysis (adjusted for hospital) } \\
\hline & OR & $95 \% \mathrm{Cl}$ & $\mathrm{p}$ Value & OR & $95 \% \mathrm{Cl}$ & p Value & OR & $95 \% \mathrm{Cl}$ & $\mathrm{p}$ Value \\
\hline Hx type 2 diabetes & 1.39 & $1.09-1.77$ & 0.008 & 1.37 & $1.05-1.74$ & 0.02 & 1.37 & $1.04-1.81$ & 0.03 \\
\hline Hx cervical spine surgery & 0.71 & $0.56-0.89$ & 0.003 & 0.66 & $0.52-0.83$ & $<0.001$ & & & \\
\hline No. of levels operated & 1.37 & $1.28-1.48$ & $<0.001$ & 1.38 & $1.29-1.49$ & $<0.001$ & 1.32 & $1.22-1.43$ & $<0.001$ \\
\hline EBL (per $10 \mathrm{ml})$ & 1.01 & $1.00-1.01$ & 0.01 & & & & & & \\
\hline
\end{tabular}

$0.16 \%, \mathrm{p}=0.26)$, SSI $(1.61 \%$ vs $2.58 \%, \mathrm{p}=0.16)$, wound dehiscence $(1.19 \%$ vs $0.65 \%, \mathrm{p}=0.27)$, and other reasons $(0.34 \%$ vs $0.0 \%, p=0.15)$ were not statistically significantly different. After adjusting for history of type 2 diabetes and total number of levels operated, which were both associated with surgical site drain placement, surgical site drains were associated with a reduced odds of reoperation for SSI (OR $0.48, p=0.04)$ but not reoperation for any reason $(\mathrm{OR} 0.89, \mathrm{p}=0.66)$, hematoma $(\mathrm{OR} 1.22, \mathrm{p}=$ $0.77)$, seroma (OR 2.99, $\mathrm{p}=0.35$ ), or wound dehiscence (OR 1.52, $\mathrm{p}=0.47$ ) (Table 4). In addition to reoperation for hematoma, seroma, infection, and wound dehiscence, patients returned to the operating room for other reasons: retained drains $(\mathrm{n}=2), \mathrm{CSF}$ fistula $(\mathrm{n}=1)$, and stitch $a b-$ scess $(n=1)$.

The median total lengths of stay in the drain and nodrain groups were 4 days (IQR 3-6 days) and 4 days (IQR $2-7$ days), respectively $(\mathrm{p}=0.14)$. To account for time spent in the hospital for preoperative workup in some patients, we also calculated the postoperative length of stay. The median postoperative lengths of stay were 4 days (IQR 3-5 days) and 4 days (IQR 2-6 days), respectively ( $\mathrm{p}=$ 0.22 ) (Table 3). On multivariate analysis adjusting for history of type 2 diabetes, total number of levels operated, and hospital, the total length of stay and postoperative length of stay were not statistically different between the drain and no-drain groups (Table 4).

\section{Clinical and Demographic Factors Associated With Reoperation}

Patient demographics were not statistically significantly different between patients who were taken back to the operating room for reoperation and those who were not (Table 5). However, the reoperation group had more total

\section{TABLE 3. Outcomes associated with drain placement}

\begin{tabular}{lccc}
\hline & $\begin{array}{c}\text { Drain } \\
(\mathrm{n}=1180)\end{array}$ & $\begin{array}{c}\text { No Drain } \\
(\mathrm{n}=619)\end{array}$ & $\begin{array}{c}\mathrm{p} \\
\text { Value }\end{array}$ \\
\hline Total reops, $\mathrm{n}(\%)$ & $48(4.07)$ & $24(3.88)$ & 0.85 \\
\hline Infection & $19(1.61)$ & $16(2.58)$ & 0.16 \\
\hline Hematoma & $8(0.68)$ & $3(0.48)$ & 0.62 \\
\hline Seroma & $6(0.51)$ & $1(0.16)$ & 0.26 \\
\hline Wound dehiscence & $14(1.19)$ & $4(0.65)$ & 0.27 \\
\hline Other reasons, $\mathrm{n}(\%)$ & $4(0.34)$ & $0(0.0)$ & 0.15 \\
\hline Median (IQR) total length of stay, days & $4(3-6)$ & $4(2-7)$ & 0.14 \\
\hline Median (IQR) postop length of stay, days & $4(3-5)$ & $4(2-6)$ & 0.22 \\
\hline
\end{tabular}

levels operated than the non-reoperation group (5 [IQR 4-6] vs 4 [IQR 3-5], respectively; $p=0.001$ ). This variable was independently associated with increased odds of returning to the operating room for reoperation (OR 1.33, $\mathrm{p}<0.001)$.

\section{Surgical Site Infection}

Patients who underwent reoperation for SSI had a higher rate of type 2 diabetes $(16 / 35,45.7 \%)$ than patients who did not have an SSI $(380 / 1764,21.5 \%)(\mathrm{p}=0.001)$. Reoperation for SSI was also associated with more total levels operated (5 [IQR 4-7] vs 4 [IQR 3-5] levels, p = $0.01)$. The total number of levels operated was also independently associated with increased odds of reoperation for SSI after adjusting for type 2 diabetes and EBL (OR $1.38, \mathrm{p}=0.001)$.

\section{Hematoma and Seroma}

There was no difference in demographic or clinical variables when comparing patients who underwent reoperation for hematoma or seroma and those who did not.

\section{Wound Dehiscence}

Patients who returned to the operating room for wound dehiscence had more total levels operated (median 5.5 [IQR 4-7]) than those who did not have wound dehiscence (median 4 [IQR 3-5]) $(\mathrm{p}=0.01)$. Patients undergoing reoperation for wound dehiscence also had a higher rate of prior cervical spine surgery $(10 / 18,55.6 \%)$ than those who did not have wound dehiscence $(411 / 1781,23.1 \%)$ (p $=0.001$ ). Neither history of type 2 diabetes nor history of rheumatoid arthritis was associated with wound dehiscence.

Four hundred ninety-two of 1180 (41.7\%) patients with drains placed had daily drainage data available for collection. The average daily drainage was $119.3 \pm 75.4 \mathrm{ml}$. Average daily drainage was increased in patients who eventually underwent reoperation compared with those who did not $(152.8 \pm 116.2 \mathrm{ml}$ vs $117.9 \pm 73.0 \mathrm{ml}$, respectively; $\mathrm{p}=0.04)$. Total drainage was also increased in patients who underwent reoperation $(273.9 \pm 172.0 \mathrm{ml}$ vs $500.8 \pm$ $647.9 \mathrm{ml}, \mathrm{p}<0.001)$. Patients returning to the operating room for treatment of SSI had increased daily drainage $(201.9 \pm 171.2 \mathrm{ml}$ vs $118.1 \pm 72.8 \mathrm{ml}, \mathrm{p}=0.003)$ and total drainage $(723.6 \pm 1003.2 \mathrm{ml}$ vs $276.3 \pm 176.3 \mathrm{ml}, \mathrm{p}<$ 0.001 ) when compared with patients who did not return to the operating room for SSI. The median postoperative day for surgical site drain removal was day 3 (IQR 2-3). There was no difference in duration of drainage between patients who underwent reoperation and those who did not. 
TABLE 4. Outcomes associated with drain placement, adjusted for comorbidities

\begin{tabular}{lccc}
\hline & $\begin{array}{c}\text { OR } \\
\text { (drain vs no drain) }\end{array}$ & $95 \% \mathrm{Cl}$ & $\mathrm{p}$ Value \\
\hline Reop & 0.89 & 0.53 to 1.49 & 0.66 \\
\hline Infection & 0.48 & 0.25 to 0.95 & 0.04 \\
\hline Hematoma & 1.22 & 0.31 to 4.82 & 0.77 \\
\hline Seroma & 2.99 & 0.30 to 29.19 & 0.35 \\
\hline Wound dehiscence & 1.52 & 0.49 to 4.67 & 0.47 \\
\hline & Coefficient & & \\
\hline Total length of stay & (drain vs no drain) & $95 \% \mathrm{Cl}$ & $\mathrm{p} \mathrm{Value}$ \\
\hline Postop length of stay & -0.65 & -1.48 to 0.18 & 0.13 \\
\hline
\end{tabular}

${ }^{*}$ Adjusted for diabetes mellitus and total number of operated levels.

$†$ Adjusted for diabetes mellitus, total number of operated levels, and hospital.

\section{Discussion}

The present study is the largest study to date on reoperation rates in patients undergoing posterior cervical spine surgery with and without postoperative drain use. This study has 2 significant findings. First, we found that surgical site drain placement is variable between hospitals and also variable within practices; however, overall, diabetic patients and patients undergoing larger surgeries in our sample were more likely to have a surgical site drain placed. The positive relationship between diabetes and SSI is congruent with previous reports in the literature..$^{24,27}$ Second, we found an association between surgical site drain use and decreased odds of reoperation for SSI. Further analysis demonstrated the overall rate of hematoma and seroma formation was $1.00 \%$, which was not different between groups and is in agreement with previous reports of postoperative hematoma ranging from $0 \%$ to $1.0 \% .^{1,5,8,11,16}$ The overall rate of infection was $1.95 \%$, which is at the low end of reported infection rates in the literature ranging from $0.5 \%$ to $18.8 \% .^{2-4,9,13,18,19,23-25,27,28}$

The orthopedic literature has a long history of investigating the use of postoperative surgical site drains. ${ }^{7}$ In total joint arthroplasty, surgical site drains were associated with increased rates of transfusion ${ }^{12,22}$ but not a decrease in the rate of wound complications. A systematic review of the orthopedic literature comparing closed suction drainage systems with no drainage system for all types of elective and emergency orthopedic surgery concluded that there was insufficient evidence from randomized trials to recommend the routine use of surgical site drains. ${ }^{21}$ Similarly, a meta-analysis of randomized controlled trials of surgical site drainage after hip fracture surgery found that drains were not beneficial. ${ }^{6}$ Conversely, in the plastic surgery literature, a large meta-analysis of 6930 patients suggested that surgical site drains are associated with decreased hematoma and seroma formation in patients undergoing breast biopsy and axillary node dissections, respectively. ${ }^{15}$ The benefit of surgical site drains appears to be surgery specific.

In comparison to other surgical sites, postoperative hematoma formation, fluid collection, and infection in a
TABLE 5. Comparison of demographic, clinical, and operative variables, by wound-related reoperation group

\begin{tabular}{|c|c|c|c|}
\hline & $\begin{array}{l}\text { No Reop } \\
(n=1727)\end{array}$ & $\begin{array}{l}\text { Reop } \\
(n=72)\end{array}$ & $\begin{array}{c}p \\
\text { Value }\end{array}$ \\
\hline Mean age \pm SEM, yrs & $63.2 \pm 0.3$ & $62.8 \pm 1.3$ & 0.81 \\
\hline Female sex, $\mathrm{n}(\%)$ & $696(40.3)$ & $26(36.1)$ & 0.48 \\
\hline Mean BMI $\pm \mathrm{SEM}, \mathrm{kg} / \mathrm{m}^{2}$ & $28.6 \pm 0.2$ & $28.8 \pm 1.1$ & 0.83 \\
\hline Current smoker, n (\%) & $375(22.2)$ & $11(15.3)$ & 0.21 \\
\hline Hx type 2 diabetes, n (\%) & $376(22.0)$ & $20(27.8)$ & 0.25 \\
\hline Hx rheumatoid arthritis, $n(\%)$ & $126(7.4)$ & $7(9.7)$ & 0.46 \\
\hline Hx cervical spine surgery, $n(\%)$ & $401(23.5)$ & $19(26.4)$ & 0.58 \\
\hline Median no. (IQR) of op levels & $4(3-5)$ & $5(4-6)$ & 0.001 \\
\hline Mean EBL \pm SEM, ml & $236.6 \pm 9.2$ & $207.1 \pm 26.7$ & 0.53 \\
\hline Drain placement, n (\%) & $1132(65.6)$ & $48(66.7)$ & 0.85 \\
\hline $\begin{array}{l}\text { Median (IQR) total length of } \\
\text { stay, days }\end{array}$ & $4(3-5)$ & $4(3-6)$ & 0.07 \\
\hline $\begin{array}{l}\text { Median (IQR) postop length of } \\
\text { stay, days }\end{array}$ & $4(3-7)$ & $5(3-7)$ & 0.21 \\
\hline
\end{tabular}

small space can result in extraordinary neurological sequelae secondary to compression of the thecal sac. In the case of postoperative cervical spine epidural hematoma, for example, rapid emergency evacuation of the blood clot is required to prevent morbid outcomes, such as quadriplegia. Studies in the lumbar spine have yet to demonstrate benefits associated with postoperative surgical site drain use. A large retrospective study of 560 patients undergoing single-level lumbar decompression surgery concluded that postoperative surgical site drains did not influence postoperative wound infection or hematoma. ${ }^{14}$ To better understand how effective drains are in reducing subclinical epidural fluid collections, Mirzai et al. prospectively randomized 50 patients undergoing single-level lumbar discectomy to have a drain placed or not and performed MRI at 1 day. They found that the group without drains developed epidural fluid collection by MRI detection at a much higher rate of $89 \%$ than the drain group at $36 \% .^{17}$ Their data suggested that drains could help clear excess fluid from the surgical site and adjacent spaces. However, they did not observe a difference in clinical outcomes between the 2 groups. A meta-analysis of 7 studies of postoperative suction drain use after posterior spine surgery included 2098 patients and found that drains did not affect healing rates or infection..$^{10}$ The relationship between surgical drains and hematoma prevention was not studied. Similarly, another recent meta-analysis failed to demonstrate an association between surgical site drains and decreased odds of hematoma and infection. ${ }^{26}$ While the benefit of surgical site drains in the lumbar spine remains to be demonstrated, the benefit of surgical site drains in the cervical spine remains an unanswered question.

The study of surgical site drains in the posterior cervical spine is limited. In their recent study, Payhs et al. suggested that surgical site drains in the posterior cervical spine in combination with alcohol foam or vancomycin powder are associated with reduced odds of SSI among patients undergoing any posterior cervical spine surgery. ${ }^{20}$ 
Our data regarding reoperation for infection are congruent with Pahys et al. as we find that surgical site drains are associated with reduced odds of reoperation for infection in a subset of patients undergoing posterior cervical spine decompression with instrumentation. This study is focused on patients undergoing larger surgeries with instrumentation, which are more prone to infection, and it is more broadly applicable to the general population, as we included data from 4 hospitals and 50 surgeons.

Our study also examined the relationship between surgical site drains and postoperative hematoma and wound dehiscence. We did not find a relationship between surgical site drain use and postoperative hematoma formation. It is possible that drains were omitted in patients in which the surgeon presumed excellent hemostasis was achieved on closing the fascia, leaving few patients who would benefit from drainage without a drain. However, this decisionmaking is unmeasurable. Regarding wound dehiscence, our data suggest that wound dehiscence is associated with larger surgeries and patients who have undergone prior cervical spine surgery. It is unknown whether prior cervical spine surgeries were performed at levels involved with the surgery under study. Operating in the vicinity of scar tissue could inhibit wound healing.

This study is limited in the following ways: 1) There is potential for bias in determining whether reoperations were possibly related to postoperative wound care. While we blinded the adjudicator to drain placement status, it is possible the operative notes provided information about postoperative wound care that could influence patient categorization. 2) While all patients received prophylactic antibiotics within 1 hour prior to skin incision per the SCIP protocol, perioperative antibiotic treatment is not standardized between patients and is difficult to obtain and quantify. 3) Due to the retrospective nature of this study, unmeasurable factors that contribute to the decision to place surgical site drains in patients after posterior cervical spine surgery cannot be evaluated. Furthermore, retrospective studies expose the study to bias and confounders that we are not aware of and can therefore not adjust for. Our study is also limited in that there were relatively small numbers of patients with infection in both populations at $1.60 \%$ with drains versus $2.58 \%$ without drains.

\section{Conclusions}

Postoperative surgical site drain use is variable in patients undergoing posterior cervical spine surgery for decompression with instrumentation; however, patients with diabetes and patients undergoing larger operations are more likely to have a drain placed. Surgical site drain placement is associated with approximately $50 \%$ reduced odds of reoperation for SSI, although the absolute number of infections in both populations was small. Furthermore, patients undergoing larger surgeries and patients who have had prior cervical spine surgery demonstrated a higher rate of reoperation for wound dehiscence. We did not find any demographic or clinical factors associated with postoperative hematoma. We recommend that surgeons consider drain placement in patients undergoing posterior cervical spine decompression with instrumentation.

\section{References}

1. Aono H, Ohwada T, Hosono N, Tobimatsu H, Ariga K, Fuji T, et al: Incidence of postoperative symptomatic epidural hematoma in spinal decompression surgery. J Neurosurg Spine 15:202-205, 2011

2. Beiner JM, Grauer J, Kwon BK, Vaccaro AR: Postoperative wound infections of the spine. Neurosurg Focus 15(3):E14, 2003

3. Best NM, Sasso RC: Success and safety in outpatient microlumbar discectomy. J Spinal Disord Tech 19:334-337, 2006

4. Bircher MD, Tasker T, Crawshaw C, Mulholland RC: Discitis following lumbar surgery. Spine (Phila Pa 1976) 13:98-102, 1988

5. Chimenti P, Molinari R: Post-operative spinal epidural hematoma causing American Spinal Injury Association B spinal cord injury in patients with suction wound drains. J Spinal Cord Med 36:213-219, 2013

6. Clifton R, Haleem S, McKee A, Parker MJ: Closed suction surgical wound drainage after hip fracture surgery: a systematic review and meta-analysis of randomised controlled trials. Int Orthop 32:723-727, 2008

7. Cobb JP: Why use drains? J Bone Joint Surg Br 72:993995, 1990

8. Cramer DE, Maher PC, Pettigrew DB, Kuntz C IV: Major neurologic deficit immediately after adult spinal surgery: incidence and etiology over 10 years at a single training institution. J Spinal Disord Tech 22:565-570, 2009

9. Dauch WA: Infection of the intervertebral space following conventional and microsurgical operation on the herniated lumbar intervertebral disc. A controlled clinical trial. Acta Neurochir (Wien) 82:43-49, 1986

10. Glennie RA, Dea N, Street JT: Dressings and drains in posterior spine surgery and their effect on wound complications. J Clin Neurosci 22:1081-1087, 2015

11. Glotzbecker MP, Bono CM, Wood KB, Harris MB: Postoperative spinal epidural hematoma: a systematic review. Spine (Phila Pa 1976) 35:E413-E420, 2010

12. Hallstrom BR, Steele JF: Postoperative course after total hip arthroplasty: wound drainage versus no drainage. Orthop Rev 21:847-851, 1992

13. Jiménez-Mejías ME, de Dios Colmenero J, Sánchez-Lora FJ, Palomino-Nicás J, Reguera JM, García de la Heras J, et al: Postoperative spondylodiskitis: etiology, clinical findings, prognosis, and comparison with nonoperative pyogenic spondylodiskitis. Clin Infect Dis 29:339-345, 1999

14. Kanayama M, Oha F, Togawa D, Shigenobu K, Hashimoto T: Is closed-suction drainage necessary for single-level lumbar decompression?: review of 560 cases. Clin Orthop Relat Res 468:2690-2694, 2010

15. Kosins AM, Scholz T, Cetinkaya M, Evans GRD: Evidencebased value of subcutaneous surgical wound drainage: the largest systematic review and meta-analysis. Plast Reconstr Surg 132:443-450, 2013

16. Kou J, Fischgrund J, Biddinger A, Herkowitz H: Risk factors for spinal epidural hematoma after spinal surgery. Spine (Phila Pa 1976) 27:1670-1673, 2002

17. Mirzai H, Eminoglu M, Orguc S: Are drains useful for lumbar disc surgery? A prospective, randomized clinical study. J Spinal Disord Tech 19:171-177, 2006

18. Olsen MA, Mayfield J, Lauryssen C, Polish LB, Jones M, Vest J, et al: Risk factors for surgical site infection in spinal surgery. J Neurosurg 98 (2 Suppl):149-155, 2003

19. Olsen MA, Nepple JJ, Riew KD, Lenke LG, Bridwell KH, Mayfield J, et al: Risk factors for surgical site infection following orthopaedic spinal operations. J Bone Joint Surg Am 90:62-69, 2008

20. Pahys JM, Pahys JR, Cho SK, Kang MM, Zebala LP, Hawasli $\mathrm{AH}$, et al: Methods to decrease postoperative infections fol- 
lowing posterior cervical spine surgery. J Bone Joint Surg Am 95:549-554, 2013

21. Parker MJ, Livingstone V, Clifton R, McKee A: Closed suction surgical wound drainage after orthopaedic surgery. Cochrane Database Syst Rev (3):CD001825, 2007

22. Quinn M, Bowe A, Galvin R, Dawson P, O'Byrne J: The use of postoperative suction drainage in total knee arthroplasty: a systematic review. Int Orthop 39:653-658, 2015

23. Rechtine GR, Bono PL, Cahill D, Bolesta MJ, Chrin AM: Postoperative wound infection after instrumentation of thoracic and lumbar fractures. J Orthop Trauma 15:566-569, 2001

24. Sebastian A, Huddleston P III, Kakar S, Habermann E, Wagie A, Nassr A: Risk factors for surgical site infection after posterior cervical spine surgery: an analysis of 5,441 patients from the ACS NSQIP 2005-2012. Spine J 16:504-509, 2016

25. Silber JS, Anderson DG, Vaccaro AR, Anderson PA, McCormick P: Management of postprocedural discitis. Spine J 2:279-287, 2002

26. Waly F, Alzahrani MM, Abduljabbar FH, Landry T, Ouellet J, Moran K, et al: The outcome of using closed suction wound drains in patients undergoing lumbar spine surgery: a systematic review. Global Spine J 5:479-485, 2015

27. Watanabe M, Sakai D, Matsuyama D, Yamamoto Y, Sato M, Mochida J: Risk factors for surgical site infection following spine surgery: efficacy of intraoperative saline irrigation. J Neurosurg Spine 12:540-546, 2010

28. Weinstein JN, Tosteson TD, Lurie JD, Tosteson AN, Hanscom B, Skinner JS, et al: Surgical vs nonoperative treatment for lumbar disk herniation: the Spine Patient Outcomes Research Trial (SPORT): a randomized trial. JAMA 296:24412450, 2006

\section{Disclosures}

Dr. Mroz: consultant for and royalties from Stryker. Dr. Florman: consultant for Stryker and direct stock ownership in Electrocore.

\section{Author Contributions}

Conception and design: Herrick, Roguski, Mroz, Lavelle, Florman, Riesenburger. Acquisition of data: Herrick, Tanenbaum, Mankarious, Vallabh, Fleischman, Kurra, Burke. Analysis and interpretation of data: Herrick, Riesenburger. Drafting the article: Herrick, Riesenburger. Critically revising the article: Herrick, Tanenbaum, Mankarious, Burke, Roguski, Mroz, Lavelle, Florman, Riesenburger. Reviewed submitted version of manuscript: Herrick, Riesenburger. Approved the final version of the manuscript on behalf of all authors: Herrick. Statistical analysis: Herrick. Administrative/technical/material support: Riesenburger. Study supervision: Riesenburger.

\section{Supplemental Information}

\section{Previous Presentations}

Portions of this work were presented in abstract form (platform presentations) at the New England Neurosurgical Society Annual Meetings, Harwich, MA, June 23-25, 2016, and Chatham, MA, June 22-24, 2017; poster presentation at the 2017 CNS Annual Meeting, Boston, MA, October 7-11, 2017; and podium presentation at Spine Summit 2018-34th Annual Meeting of the Section on Disorders of the Spine and Peripheral Nerves, Orlando, FL, March 14-17, 2018.

\section{Correspondence}

Daniel Herrick: Tufts Medical Center, Boston, MA. daniel. herrick@tufts.edu. 